\title{
Heat Analysis and Fire Prevention of Timber Buildings in Southwest China Based on Fractal and Seepage Theory
}

\author{
Yingchun $\mathrm{Cao}^{1,2^{*}}$, Xiaoling Chen ${ }^{1}$, Jie Yang ${ }^{1}$, Haoyan Zhang ${ }^{3}$ \\ ${ }^{1}$ School of Architecture and Art, Hebei University of Architecture, Zhanjiakou 075000, China \\ ${ }^{2}$ College of Civil Engineering and Architecture, Hebei University, Baoding 071002, China \\ ${ }^{3}$ School of Architecture and Urban Planning, Suzhou University of Science and Technology, Suzhou 215009, China
}

Corresponding Author Email: xjyang@hbu.edu.cn

https://doi.org/10.18280/ijht.390204

Received: 25 November 2020

Accepted: 2 February 2021

\section{Keywords:}

fire, traditional Chinese settlements, fractal and seepage theory

\begin{abstract}
In traditional settlements in Southwest China, there are many timber historical buildings and residential buildings, which feature a low fire resistance rating. The preservation and inheritance of these timber buildings are mainly threatened by fire. However, the existing research has not explored the deep correlation between the spatial structure of settlements and fire. To make up for the gap, this paper aims to find the ideas and measures that effectively prevent the fire from occurring in timber buildings of traditional settlements in Southwest China, based on fractal and seepage theory. Firstly, the fractal features were extracted from the spatial structure of these settlements. Then, the authors identified the factors affecting the spread of fire in buildings, and analyzed the mechanism of fire propagation between the timber buildings of traditional settlements. On this basis, a fire prevention scheme was proposed, which integrates the "targeted control of overall structure" with "comprehensive synergy between multiple local elements". The research results provide a reference for applying fractal and seepage theory in the fire prevention of other buildings with special structures.
\end{abstract}

\section{INTRODUCTION}

Traditional Chinese settlements are the living fossils of the agricultural civilization and lifestyle in ancient China. It is of great value and significance to preserve and inherit these precious remains $[1,2]$. To better protect these heritages, the Chinese government has organized traditional settlements into multiple heritage lists, including the list of famous historical and cultural villages, towns, and cities, and the list of traditional Chinese villages. Fire is an unavoidable hazard in the inheritance of traditional Chinese settlements, posing the most serious and devastating risk to these settlements [3-7].

In recent years, researchers have designed multi-faceted prevention measures and protection specifications of fire, and achieved significant technical progress [8-11]. For example, $\mathrm{Xu}$ et al. [12] investigated the fire spread features (e.g., fire spread rate, heat release rate, and temperature field) of the exterior thermal insulation materials of high-rise buildings in different stage of fire, constructed a reasonable structural model for the façade, analyzed the thermal feedbacks of the preheating zone of fire, and evaluated the impacts of side wall restriction effect on fire-induced gas flow velocity under the changing building structure. Liang et al. [13] numerically simulated the temperature field of community fires, divided the combustion of solid materials in buildings into an initial phase and a spread phase, examined the fire spread rate, indoor air flow variation, and temperature field distribution in each phase, and compared the fire spread features on the façade under environmental pressure, outdoor wind direction, and outdoor wind velocity.

Many timber historical buildings and residential buildings feature a low fire resistance rating. In particular, the traditional settlements of ethnical minorities like Dong and Miao are faced with tremendous threat from fire, owing to their unique spatial structure. If a fire breaks out, these settlements might suffer from immeasurable casualty and property loss. The Dong and Miao settlements are often located on slopes, in valleys, or across flat areas. Except the tiles on the roof, the buildings are almost entirely made of timber, lap jointed by numerous tall and short timber components. Due to the large difference between building timbers in pyrolysis parameters, the numerical simulation of fire spread features using experimental data often has a large error [14-16].

Qin et al. [17] conducted kinetic fitting for the materials of timber buildings in different stages of pyrolysis, established the relevant kinetic equations for pyrolysis, built a simulation model for the fire propagation inside timber buildings, and compared the fire spread features of timber buildings under different fire source locations and ventilation conditions, as well as their influencing factors. Tian et al. [18] numerically simulated the reaction heat and reference temperature of timber buildings in Lijiang, southwestern China's Yunnan Province, calculated the surface temperature rise of timber buildings under variable heat flow, derived a scientific fire separation distance for timber buildings, and used Fire Dynamics Simulator (FDS) to simulate the influence of full combustion of timber buildings over the environment within the fire separation distance. Guo et al. [19] analyzed the structural and material features of stilted timber buildings, conducted numerical simulation of the pyrolysis kinetics, as well as the distribution of indoor/outdoor temperature and flue gas, studied the temperature distribution around the building 
at different slopes and fire separation distances, and estimated the burning-out time of the fire source.

In traditional settlements, the fire is violent and fast spreading. Once a fire occurs, the entire village is under threat. Some scholars have noticed the uniqueness of settlement fire, and designed refined measures for performance-based fire prevention. However, none of them went further to explore the deep correlations between the spatial structure of the settlements and fire. Drawing on fractal and seepage theory, this paper takes some typical settlements of traditional Chinese villages as the object, investigates the influencing factors and mechanism of the fire spread in timber buildings of traditional settlements, and looks for the genetic mechanism of traditional settlement fires from the perspective of structure. The research intends to kick off systematic studies on the structural fire mechanism of traditional Chinese settlements.

\section{THEORETICAL BACKGROUND}

The fractal theory, which combines systems theory with self-organizing fractal theory, can describe complex systems with self-similarity under different dimensions. The fractal structure is featured by scale behaviors. The structure can iteratively evolve into complex forms, according to the power law and self-similar rules. The number of fractal dimensions is usually a fraction denoted as D. There are various ways to calculate that number. The most common and effective method is to compute the compute the box-counting dimension: First, the fractal is covered by square grids of equal size; then, the grid size is gradually reduced, and the number of grids that can cover the fractal is calculated in each round. The box-counting dimension can be calculated by:

$$
\operatorname{Dim}_{b o x}^{F}=\lim _{\delta \rightarrow 0} \frac{\log N_{\delta}(F)}{\log (1 / \delta)}
$$

Due to the sheer number of grids, the box-counting dimension is usually calculated automatically by fractal software. With the aid of Fractalyse 2.4.1, this paper probes deep into the self-organized evolution of fractal from the angles of morphology, structure, and time series.

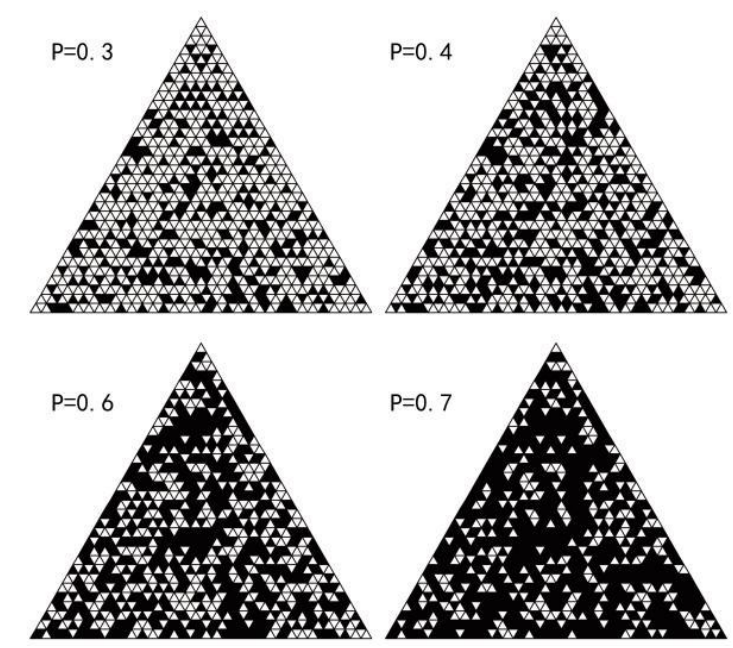

Figure 1. Relationship between the probability of each grid being colored black and seepage formation and evolution
Originated in fluid analysis, the seepage theory has been extended to many other fields. By this theory, the set of many non-connected fragments is transformed into an interconnected polymer in the critical state of seepage. Taking the grid coloring in Figure 1 for example, every grid is colored black or not colored randomly. The probability for each grid to be colored black is denoted as $\mathrm{P} \in[0,1]$. If $\mathrm{P}$ equals 0 or 1 , the grids are all white or black; as $\mathrm{P}$ changes between 0 and 1 , the clusters of connected black grids grows with the increase of $\mathrm{P}$, and the small clusters gradually connect with each other, forming large clusters. When $\mathrm{P} \approx 0.5928$, the scattered clusters will merge into a huge cluster that almost covers all grids. In this case, the grid system reaches the critical state of seepage, and the critical probability is denoted as Pc. At this time, the macroscopic traits of the system undergo phase changes: the initially scattered individual behaviors are converted into overall and systematic behaviors, and a fractal structure of the dimension of 1.8 is formed. When $\mathrm{P}$ gradually increases from $\mathrm{Pc}$, the integrity of the large cluster continues to improve. The seepage theory has been widely applied to study forest fire, disease spread, and information dissemination.

\section{ANALYSIS ON INFLUENCING FACTORS}

This paper identifies four main factors affecting the indoor fire spread in timber buildings of traditional settlements, namely, source position, ventilation condition, fire load, and material property.

\subsection{Source position}

Inside the timber buildings of traditional settlements, the fire source position (e.g., horizontal surface, vertical surface, or vertical wall corner) has a certain impact on the amount of oxygen available for combustibles and the spread rate of fire. To obtain the fire spread law at each source position, the fire spread process was numerically simulated for different source positions, and the calculated results were compared at different material properties, environmental conditions, and heat release rates.

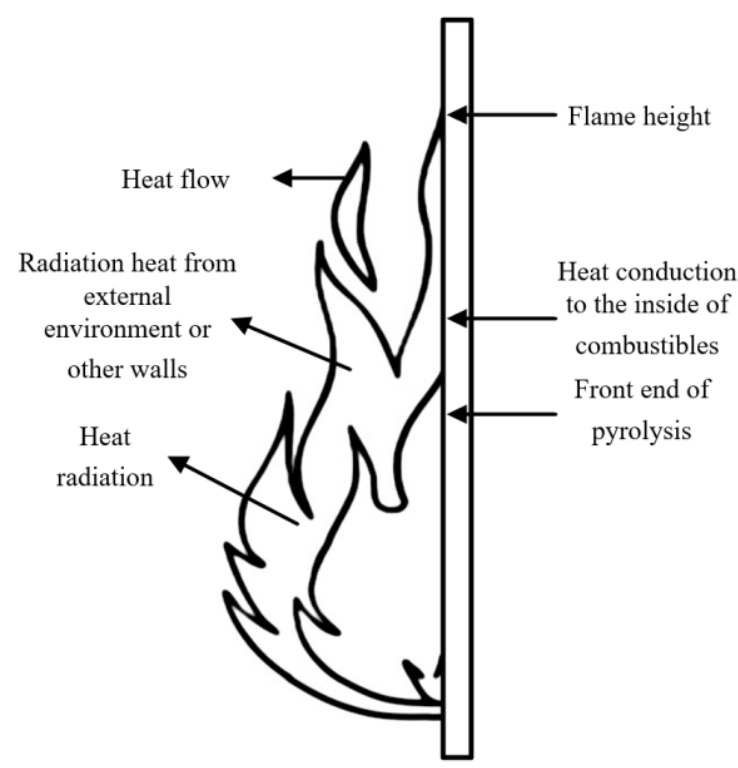

Figure 2. External form of flame 
Figure 2 illustrates the external form of a flame. As can be seen from the figure, the bottom of the flame is directly in contact with the surface of the combustible. The heat of the flame is transferred to the surroundings primarily in three forms: heat conduction, heat convection, and heat radiation (including positive radiation and reverse radiation). Let $W_{C T}$ be the heat transfer coefficient of conduction; $W_{R}$ and $W_{B R}$ be the heat transfer coefficients of positive radiation and reverse radiation, respectively. Since the flame shape depends heavily on the surrounding environment, and $W_{B R}=W_{R}$ between the fire area and flame bottom, the heat transferred by convection from the burning combustible can be simplified as:

$$
W_{C}^{\prime}=W_{C T}+W_{R}-W_{B R} \approx W_{C T}
$$

Let $\tau_{H B}$ and $\tau_{H C}$ be the temperatures on the surface and at the center of the flame, respectively; $\tau_{H A}$ and $\tau_{H N}$ be the surface temperatures of burning area and non-burning area on the surface of the combustible, respectively; $\beta$ be the heat transfer coefficient. By the principle of equivalent heat transfer, we have:

$$
\begin{aligned}
& W_{C}^{\prime}=\beta\left(\tau_{H A}-\tau_{H N}\right) \\
& =\beta\left(\frac{\tau_{H A}-\tau_{H C}}{2}-\tau_{H N}\right)
\end{aligned}
$$

During the convective heat transfer of the fire, the air receives heat from the fire source via conduction, convection, and radiation, and transfers the heat to the timber buildings of traditional settlements or other combustibles indoor via heat convection. Let $S_{C}$ be the surface area of the timber building or the indoor combustible that exchange heat with the air via convection. Then, the heat transferred from the flame of the fire source to the surrounding air can be expressed as:

$$
W_{C}^{\prime \prime}=\beta\left(\tau_{H A}-\tau_{H N}\right) \cdot S_{C}
$$

Let $N U$ and $R A$ be the Nusselt number and Rayleigh number, respectively; $d$ be the thickness of the boundary layer of heat convection; $v$ and $\gamma$ be the physical parameters of hot air under normal pressure; $a$ be the acceleration of gravity. Then, the Rayleigh number $R A$ can be calculated by:

$$
R A=\frac{a \gamma\left(\tau_{H A}-\tau_{\infty}\right) d^{3}}{v \beta} N U
$$

The above is the analysis for horizontal fire source. The vertical fire source has a similar thermal effect on the combustible as the horizontal fire source. The main difference is that, under the effect of thermal buoyancy, the flammable gas decomposed from the combustible is directly in contact with the flame, and combusted instantaneously, which speeds up the spread of fire. Compared with vertical fire source, the fire source in the vertical wall corner, which involves two vertical walls and the horizontal floor at the corner, produces a high concentration of flammable gas through thermal decomposition of the combustible. The thick flammable gas, coupled with the poor dissipation conditions, causes incomplete burning of the combustible, and thus emits lots of thick smoke. In the timber buildings of traditional settlements, the indoor fire generally spreads in a simple pattern during the initial phase, which gradually diversifies and complicates as the fire intensifies.

\subsection{Ventilation condition}

Judging by the ventilation condition, the combustion of the timber buildings and their indoor combustibles in traditional settlements is either controlled by fuel or controlled by ventilation. Let $\eta_{H}$ be the heat release rate of the fire; $S_{R}$ be the surface area of indoor space; $S_{F P}$ and $L_{F P}$ be the size and height of the vent indoor, respectively. Then, the ventilationcontrolled combustion form can be described as:

$$
\eta_{V C-H}=\frac{\delta \sqrt{a} S_{F P} \sqrt{L_{F P}}}{S_{R}}<0.24
$$

The fuel-controlled combustion form can be described as:

$$
\eta_{F C-H}=\frac{\delta \sqrt{a} S_{F P} \sqrt{L_{F P}}}{S_{R}}>0.29
$$

In general, the combustion is controlled by fuel in the initial phase of fire, as the oxygen supply is sufficient; as the fire intensifies, the combustion form gradually becomes ventilation-controlled.

\subsection{Fire load and material property}

Fire load refers to the total heat released by the timber building and all its indoor combustibles in traditional settlement, which are fully burned in the fire cycle. It characterizes the duration of fire, heat release rate, and indoor temperature rise. The indoor fire load can be determined by integrating the heat release rate calculated by the heat release rate model, or multiplying the heat of combustion with mass of the building material. The greater the fire load, the higher the fire hazard faced by the timber building in the traditional settlement. For such a timber building, the mass burning rate of the building material is equivalent to fire power, i.e., the quotient of the fire load and fire duration. Let $F L$ be the fire load; $M B$ be the burning rate. Then, the fire duration $\tau_{F D}$ can be calculated by:

$$
\tau_{F D}=\frac{F L}{M B}
$$

In a traditional settlement, the timber buildings and their indoor combustibles are mostly solid materials. The fire hazard of these materials depends on the physical state and chemical property of the building material, as well as environmental conditions like humidity, temperature, and wind. As the name suggests, timber buildings are dominated by timber, which is prone to carbonization. Unlike timber, plastic construction material will burn violently, and produce combustible melt, whose burning state is similar to that of oil pool fires.

\section{FIRE SPREAD MECHANISM}

After a fire breaks out in a timber building of the traditional 
settlement, the heat will be gradually transferred to the nearby buildings or trees, with the intensification of the fire. If the heat received by the latter reaches their burning thresholds, the fire will spread across the traditional settlement and even to the nearby forest. Figure 3 shows how a randomly ignited fire spreads across combustible elements. Considering the spatial structure of traditional settlements, a fire was ignited at a random point in an area with a regular layout of buildings, in an attempt to simulate the fire spreading in the village. Suppose the houses adjacent to the burning house will be ignited first, and, in each step thereafter, the fire will spread from a burning house to its adjacent houses. In this way, the burned houses will form a cluster of combustible elements with the ignition point as the center.
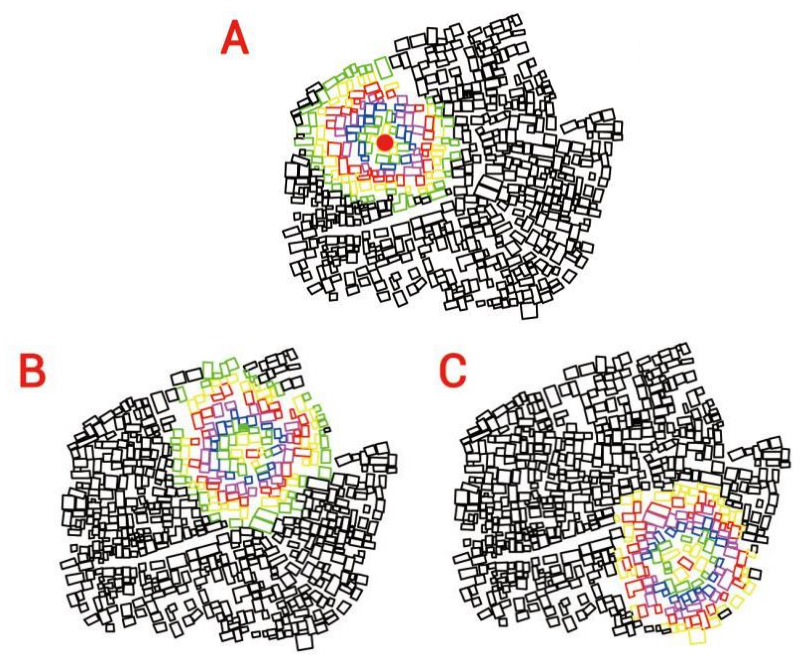

Figure 3. Propagation of randomly ignited fires across the traditional settlement

The fire propagation through the timber buildings of traditional settlements or nearby forests is caused by heat radiation, heat convection, jump fire, and direct contact combustion. Among them, heat radiation is the primary cause. To prevent the fire from spreading, the key measure is to increase the fire separation distance. The theoretical calculation method for that distance varies with the types of heat radiation. In the case of point source heat radiation, the heat radiation flux $F_{P-H R}$ at distance $L$ from the fire source can be calculated by:

$$
F_{P-H R}=\frac{P_{H R}}{4 \pi L^{2}}
$$

where, $P_{H R}$ is the heat radiation power of the fire. Then, $1 / 3$ of the energy in the heat power $P$ of the fire source of timber buildings in traditional settlement was considered heat radiation. Then, the point source heat radiation $F_{P-H}$ can be described as:

$$
F_{P-H}=\frac{P}{12 \pi L^{2}}
$$

In the case of non-point source heat radiation, the heat radiation flux can be calculated by:

$$
F_{S-H R}=\omega E_{R S}
$$

where, $F_{S-H}$ is the heat radiation flux received by the radiated surface of the buildings or forest near the burning building; $E_{R S}$ is the radiation strength of the radiant surface of the burning building; $\omega$ is a morphological coefficient related to the geometric size and relative location of the radiant and radiated surfaces. Let $\mu$ be the heat release rate per unit area. The nonpoint source heat radiation $F_{S-H}$ can be empirically described as:

$$
F_{S-H}=\omega \mu / 3
$$

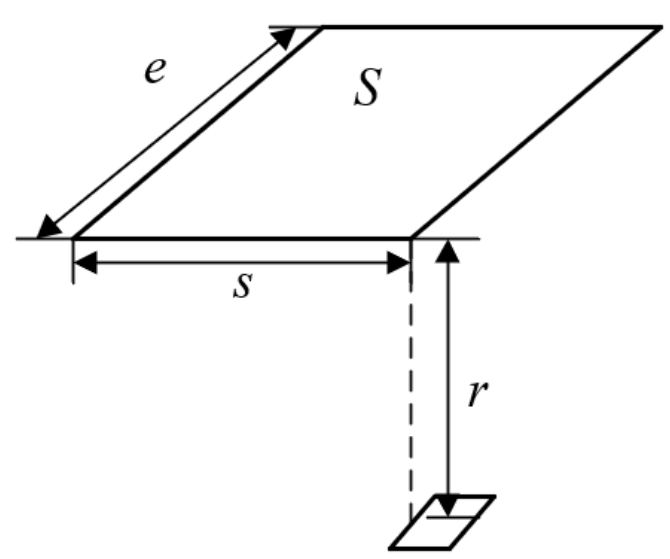

(a) Parallel relationship

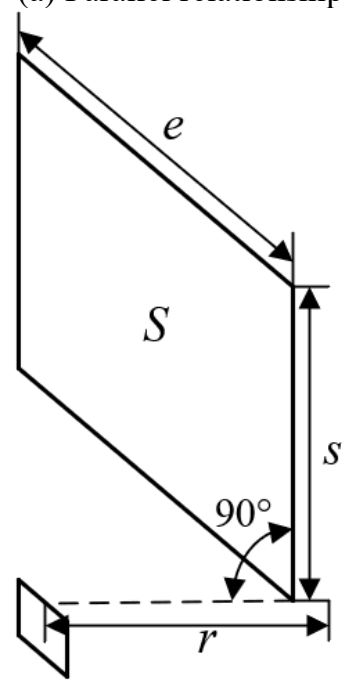

(b) Perpendicular relationship

Figure 4. Relative location between radiant and radiated surfaces

If the radiation source is rectangular, and the radiant surface is parallel to the radiated surface (Figure 4a), $\omega$ can be calculated by:

$$
\left\{\omega=\frac{1}{2 \pi}\left[\frac{A}{\sqrt{1+A^{2}}} \tan ^{-1}\left(\frac{B}{\sqrt{1+A^{2}}}\right)+\frac{B}{\sqrt{1+A^{2}}} \tan ^{-1}\left(\frac{A}{\sqrt{1+A^{2}}}\right)\right]\right.
$$

If the radiant surface is perpendicular to the radiated surface (Figure $4 b$ ), $\omega$ can be calculated by:

$$
\left\{\begin{array}{l}
A=s / r, B=e / r, U=1 / \sqrt{A^{2}+B^{2}} \\
\omega=\frac{1}{2 \pi}\left[\tan ^{-1}\left(\frac{1}{B}\right)-U B \tan ^{-1}(U)\right]
\end{array}\right.
$$




\section{EXPERIMENTS AND RESULTS ANALYSIS}

The list of traditional Chinese villages records the most representative surviving examples for the agricultural civilization of ancient China. The villages in that list present the original spatial structure of traditional settlements. This paper selects eight typical traditional Dong and Miao settlements from the list, namely, Zengchong Village, Wangdong Township, Congjiang County, Qiandongnan Miao and Dong Autonomous Prefecture. Besides, the core areas of two larger settlements, also in southwestern China, with similar culture to these villages were also taken as the objects, including Lijiang Ancient City (a famous historical and cultural city) and Dukezong Ancient City. The spatial structures of these cases were plotted, and the relevant data were calculated. The fractal dimensions $D$ and goodness-of-fit $R^{2}$ were calculated by Fractalyse 2.4 .1 for the randomly selected clusters of combustible elements and the entire settlements (as shown in Table 1).

Table 1. Fractal dimensions and goodness-of-fit for randomly selected clusters of combustible elements and the entire settlements

\begin{tabular}{|c|c|c|c|c|c|c|}
\hline \multirow{2}{*}{\multicolumn{2}{|c|}{ Serial number of traditional settlements }} & \multicolumn{3}{|c|}{ Fractal dimension of random points } & \multicolumn{2}{|c|}{ Fractal dimension of villages } \\
\hline & & \multirow{2}{*}{$\frac{\text { Random points }}{\text { A }}$} & \multirow{2}{*}{$\frac{R^{2}}{0.968}$} & \multirow{2}{*}{$\frac{D}{1.824}$} & \multirow[t]{2}{*}{$R^{2}$} & \multirow{2}{*}{$D$} \\
\hline \multirow{4}{*}{\multicolumn{2}{|c|}{1}} & & & & & \\
\hline & & B & 0.966 & 1.837 & 0.966 & 1.808 \\
\hline & & $\mathrm{C}$ & 0.959 & 1.814 & & \\
\hline & & A & 0.974 & 1.848 & & \\
\hline \multirow{3}{*}{\multicolumn{2}{|c|}{2}} & $\mathrm{~B}$ & 0.960 & 1.820 & 0.969 & 1.806 \\
\hline & & $\mathrm{C}$ & 0.975 & 1.845 & & \\
\hline & & A & 0.962 & 1.822 & & \\
\hline \multirow{3}{*}{\multicolumn{2}{|c|}{3}} & $\mathrm{~B}$ & 0.956 & 1.824 & 0.958 & 1.768 \\
\hline & & $\mathrm{C}$ & 0.956 & 1.816 & & \\
\hline & & A & 0.969 & 1.823 & & \\
\hline \multirow{3}{*}{\multicolumn{2}{|c|}{4}} & $\mathrm{~B}$ & 0.968 & 1.835 & 0.964 & 1.816 \\
\hline & & $\mathrm{C}$ & 0.969 & 1.845 & & \\
\hline & & $\mathrm{A}$ & 0.952 & 1.834 & & \\
\hline \multirow{4}{*}{\multicolumn{2}{|c|}{5}} & $\mathrm{~B}$ & 0.942 & 1.835 & 0.973 & 1.850 \\
\hline & & $\mathrm{C}$ & 0.960 & 1.844 & & \\
\hline & & A & 0.963 & 1.819 & & \\
\hline & & B & 0.954 & 1.829 & & \\
\hline \multirow{4}{*}{\multicolumn{2}{|c|}{6}} & $\mathrm{C}$ & 0.947 & 1.810 & 0.937 & 1.749 \\
\hline & & B & 0.961 & 1.849 & & \\
\hline & & $\mathrm{C}$ & 0.940 & 1.802 & & \\
\hline & & A & 0.963 & 1.795 & & \\
\hline \multirow{3}{*}{\multicolumn{2}{|c|}{7}} & B & 0.967 & 1.807 & 0.974 & 1.819 \\
\hline & & $\mathrm{C}$ & 0.988 & 1.846 & & \\
\hline & & $\mathrm{A}$ & 0.959 & 1.792 & & \\
\hline \multirow{2}{*}{\multicolumn{2}{|c|}{8}} & B & 0.954 & 1.785 & 0.959 & 1.797 \\
\hline & & $\mathrm{C}$ & 0.958 & 1.789 & & \\
\hline
\end{tabular}

As shown in Table 1, a scale-free zone was found in the data on the three random combustible elements in each of the 8 settlements and the overall data on each settlement. The goodness-of-fit $R^{2}$ almost all surpassed 0.96 . Figure 5 illustrates the global and local fractal dimensions of each settlement. It can be seen that, the fractal dimensions of the random combustible elements in each village stabilized in the interval of $[1.80,1.89]$, while those of the villages concentrated in $[1.75,1.85]$. This means both the random combustible elements and the settlements have clear fractal structures.

Further comparison shows that the dimensions of the random combustible elements averaged at 1.83, slightly higher than the mean overall dimension of settlements (1.80). The relatively low global dimensions of the settlements come from the hierarchy and heterogenous distribution of the space of the whole village: the high-grade roads and scattered public spaces on the settlement level take up more spaces than locallevel low-grade roads and public spaces, which lowers the spatial proportion of entities in each settlement. Of course, the opposite situation might occur due to the unique spatial structure of specific settlements. Note that the above calculation only considers the timber buildings themselves, without taking account of the associations and superimposed effects of nearby barns, livestock houses, debris, and fences. In actual situation, these combustibles could increase the fractal dimensions, and catalyst fire propagation.

Figures 6 and 7 show how the indoor temperature and heat radiation flux change during the fire of a timber building in the traditional settlement. As shown in Figure 6, with the fire development, the indoor temperature measured at each point first slowly increased, and surged up after the flashover at 6$7 \mathrm{~min}$. The most obvious change of temperature was observed at the wall corner of point 1 . The upper area indoor had a higher temperature and humidity than the lower area. After the flashover, the flue gas layer was as hot as $700-800^{\circ} \mathrm{C}$. The temperature quickly dropped after the fire was put out.

As shown in Figure 7, at the initial phase of the fire, the indoor heat radiation flux rose slowly. Starting from 250 s, the timber entered the stage of full combustion, and the heat radiation flux reached $2 \mathrm{~kW} / \mathrm{m}^{2}$. After the flashover at $6-7 \mathrm{~min}$, the flame quickly spread out along the timber ceiling of the building; the heat radiation flux climbed up to above $9 \mathrm{~kW} / \mathrm{m}^{2}$ within $1 \mathrm{~min}$. After that, the heat radiation flux slowly grew at a high level, and the indoor fire entered the most intense stage. The heat radiation flux plunged rapidly after the fire was extinguished. 


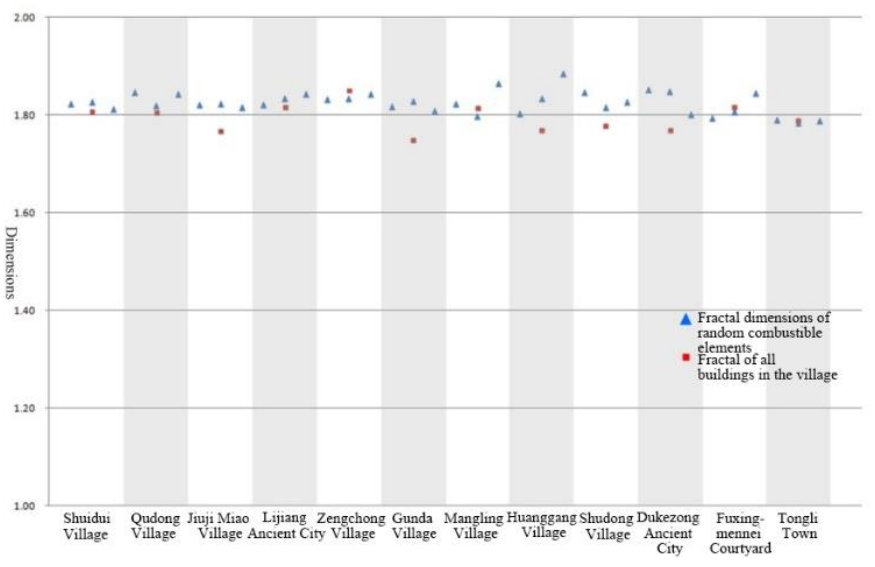

Figure 5. Global and local fractal dimensions

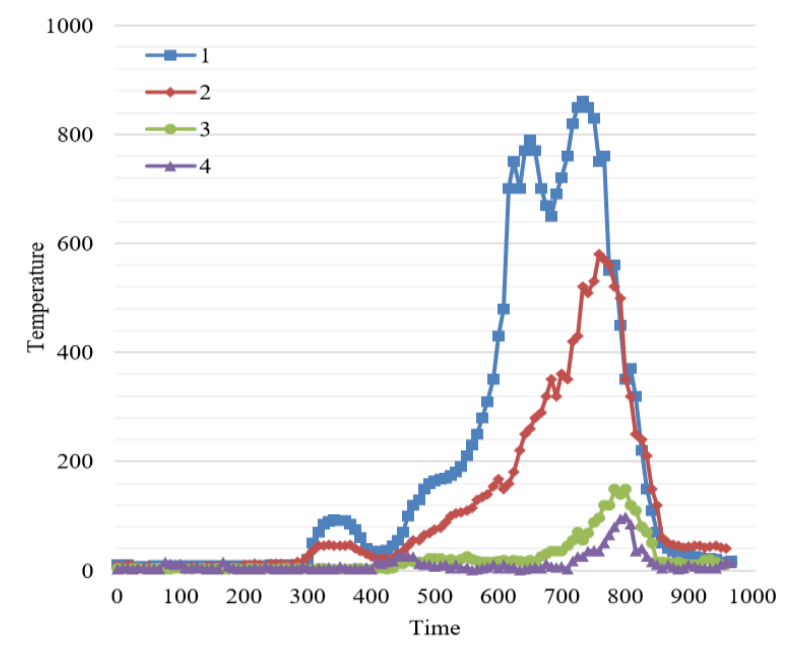

Figure 6. Indoor temperature variation of a timber building in the traditional settlement

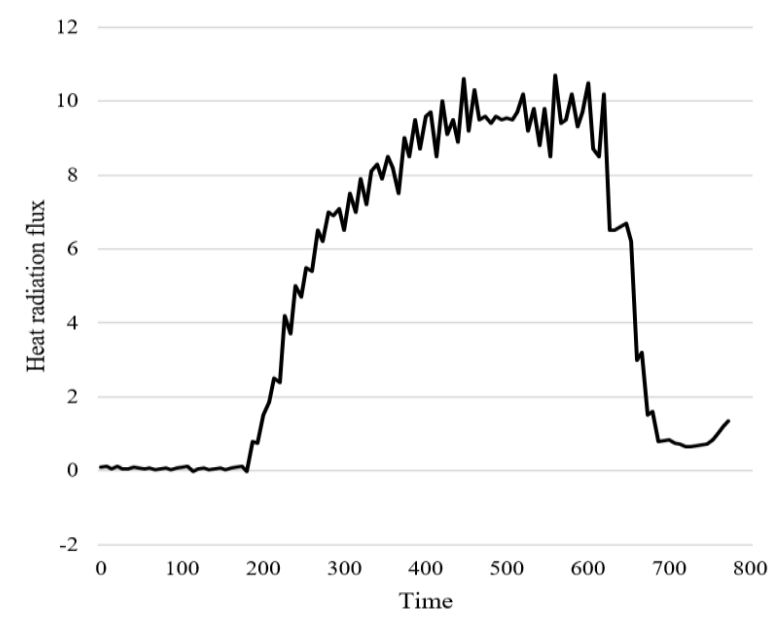

Figure 7. Heat radiation flux variation of a timber building in the traditional settlement

Figures 8 and 9 compare the simulation results on indoor temperature and heat radiation flux of timber buildings in traditional settlements with the test results, respectively. There was a certain gap between simulated indoor temperature and test data in the initial phase of the fire. Except for that, the simulated indoor temperature and heat radiation flux were basically consistent with the test results, after the flashover.
The reason is that the indoor temperature is greatly affected by the environment in the initial phase of fire. The comparison indicates that our numerical simulation can accurately depict the fire propagation through timber buildings in traditional settlements. The simulated indoor temperature, whether before, during, and after flashover, or at the moment of maximum heat release rate, agreed with the test results.

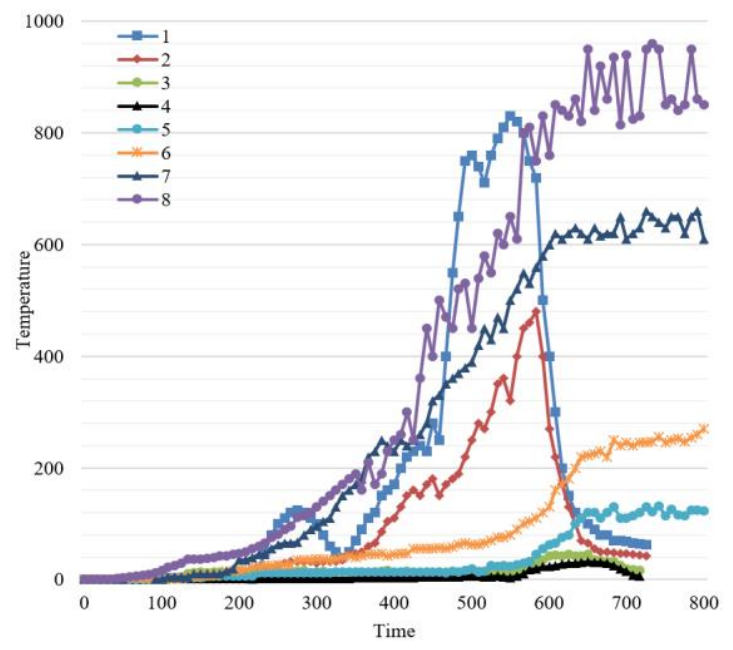

Figure 8. Comparison of indoor temperature variations under different working conditions

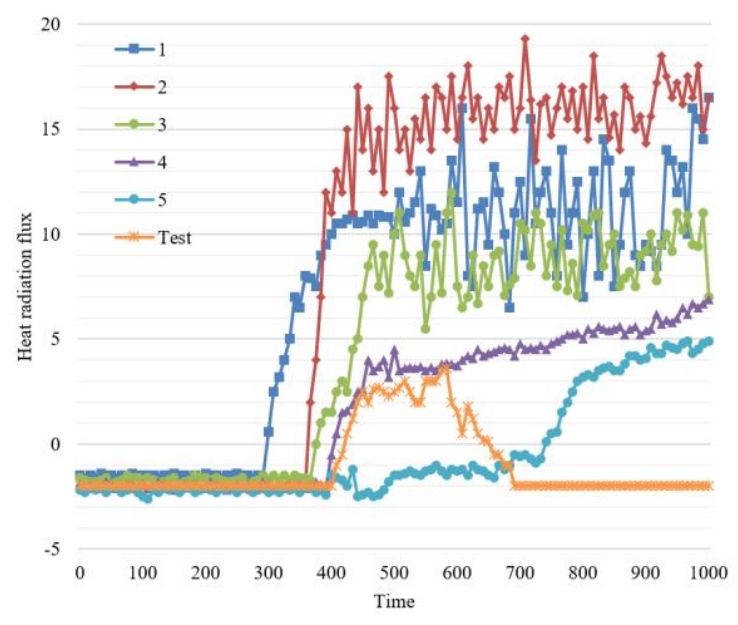

Figure 9. Comparison of heat radiation flux radiations under different working conditions

To verify the influence of source position on the fire propagation, 11 source positions were selected to simulate the fire propagation in timber buildings of traditional settlements. The simulation results (Table 2 ) show that the probability of a widespread fire changed with the source position. At positions $1,6,7,9$, and 10 , even if there is a fire source, the heat released by the combustion of the source is not enough to ignite other combustibles indoor. Positions 2, 4, and 5 are located in areas with many combustibles. However, the fire ignited at these positions only partially propagated, because they are bordered by materials that are not easy to combust. By contrast, positions 3,8 , and 11 are in direct contact with timber components; these positions are very likely to suffer from flashover, and see severe propagation of fire; even the top beam might catch fire. 
Table 2. Simulated results on fire spread through timber buildings in traditional settlements with different source positions

\begin{tabular}{cccc}
\hline Position number & Ignition position & Center coordinates of fire source & Phenomenon \\
\hline 1 & First from the left & $(2.6,11.2,0.92)$ & No propagation \\
2 & Second from the left & $(8.1,15.3,0.92)$ & Partial horizontal propagation \\
3 & Third from the left & $(-9.5,21.7,0.92)$ & Top beam ignited at 10min; flashover at 20min \\
4 & Outside on the left & $(8.1,23.4,0.92)$ & Partial horizontal propagation \\
5 & Inside on the left & $(-1.8,21.7,0.92)$ & Partial horizontal propagation \\
6 & First from the right & $(8.1,4.9,0.92)$ & No propagation \\
7 & Inside on the right & $(6.3,-21.9,0.92)$ & No propagation \\
8 & First in the middle & $(8.1,4.7,0.92)$ & Flashover at 5min \\
9 & Second in the middle & $(-1.6,4.5,10.18)$ & No propagation \\
10 & Outside in the middle & $(-1.6,17.5,10.18)$ & No propagation \\
11 & Inside in the middle & $(6.2,4.5,10.18)$ & Top beam ignited at 3min; flashover at 6min \\
\hline
\end{tabular}

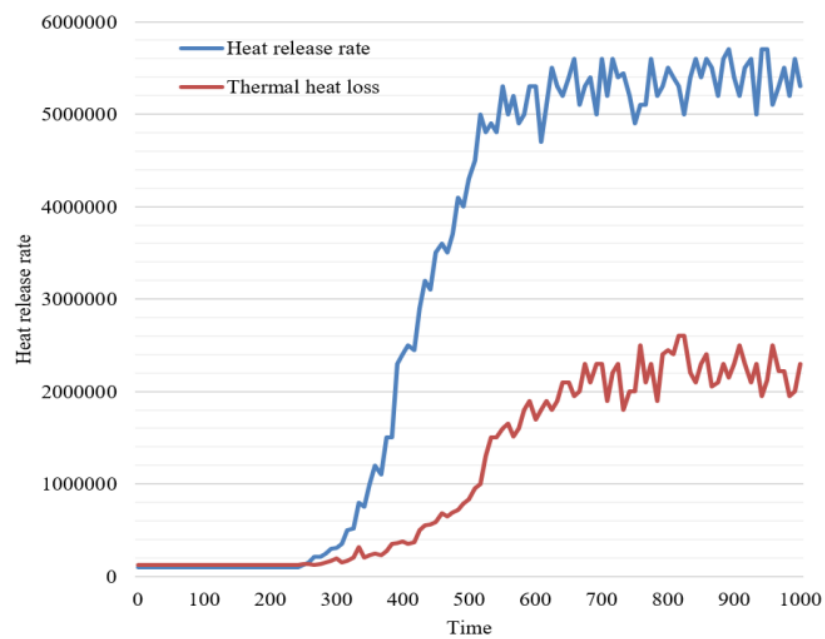

(a) Fire separation distance: $4 \mathrm{~m}$

(b)

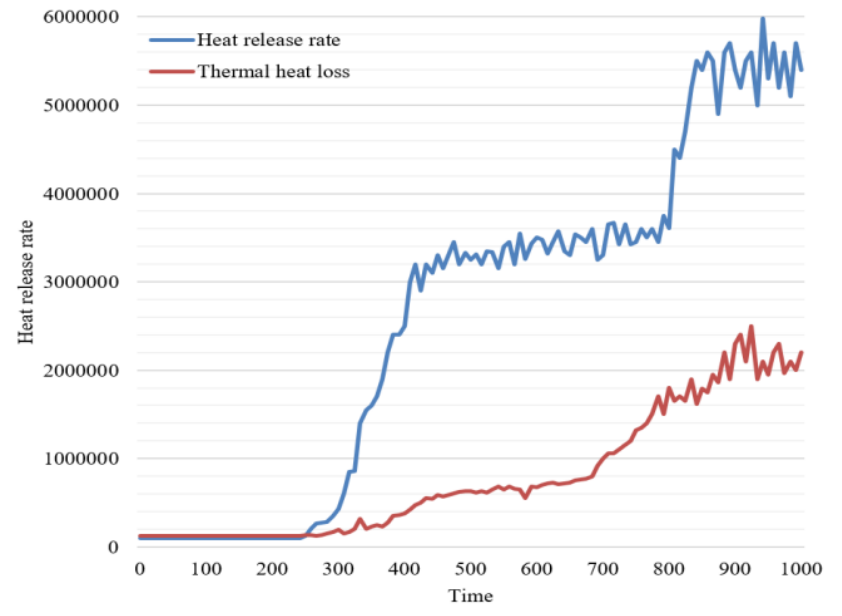

(b) Fire separation distance: $8 \mathrm{~m}$

Figure 10. Comparison of heat release rate and thermal heat loss at different fire separation distances

To verify the fire spread mechanism across timber buildings of traditional settlements, this paper tests the changes of heat release rate and thermal heat loss with the increase of fire separation distance. As shown in Figure 10, after the fire separation distance increased from $4 \mathrm{~m}$ to $8 \mathrm{~m}$, the flame did not spread to the nearby timber buildings until $14 \mathrm{~min}$ into the fire; then, the fire further propagated across the entire settlement. The fire spread was delayed by $6 \mathrm{~min}$ by increasing the fire separation distance.

\section{DISCUSSION}

\subsection{Combustion seepage critical body}

The settlement is a combustible body formed by the cascaded burning of each single building under the fire spread mechanism. Although the single buildings of the settlement are usually not directly connected with each other, the fire is a diffusive flow capable of spreading outward from the combustibles. The "cross-the-air" spread of fire is further enhanced by the non-contact radiation and conduction of heat. The fractal dimensions of random combustible elements cluster in the narrow interval of $[1.80,1.89]$. Some even reach the critical dimension for seepage flow: 1.89. In other words, the self-organized spatial structure of the traditional settlement lies close to the critical value of seepage flow. During the fire, the isolated buildings in the settlement are interconnected into a massive cluster, which exhibits as a random fractal. The fire at any position can be conducted to the overall structure, and accumulate in the system. What is worse, the fractal feature of the seepage critical body means the combustion factors will accumulate by the power law, as the fire spreads from the center to the peripherals, making the fire intensify quickly and significantly. Therefore, the accumulation of combustion factors and structural collapse of the traditional settlement are attributable to the structural nature of the settlement as a quasiseepage critical body.

\subsection{Spatial structure}

The spatial structure of Dong and Miao settlements either adopts the topology of matrix structure, or mixes this topology with various local radiation structures. Based on the matrix structure, the spatial frame of the settlement space adapts to the landform, climate, and customs through bending, reversing, and stretching. The basic framework of spatial structure of the settlements is summarized in Figure 11. The adaptation tightens the bonds between buildings, and facilitates the formation or enhancement of seepage cluster, which also increases the associations between buildings. Theoretically, the most efficient structure to occupy and utilize space is the homogenous, isotropic matrix structure; it is a common structure to reach the critical state of seepage flow. Taking the forest fire in Figure 12 as an example, the occurrence and propagation of the fire are a typical seepage phenomenon. The spatial structure of forest is topologically the same as that of traditional settlements. Suffice it to say that the spatial structure lays the basis for the structural fire of traditional settlements. 
Figures 13 and 14 present the typical parts of a courtyard in Fuxingmennei region, Beijing and Tongli Town, Jiangsu, two external references of our research. The fractal dimensions were calculated for the two settlements and three randomly selected local areas of each settlement. The calculated results are recorded in Table 2 . The two settlements strictly abided by the fractal structure, and their overall data were basically similar as those of Dong and Miao settlements. However, the data of the two references tended to cluster together. From the angle of seepage flow, Dong and Miao settlements had the same spatial structure as the references: the structure is organized based on topology matrix and close to the critical state of seepage flow. From the perspective of sociology, Dong and Miao both have a patrilineal society with a large and closely bonded ethnic group. Their settlements inevitably feature close correlations. The social space and private space are highly hierarchical, and mixed with the feeling of territory. The spatial structure carries many features of the social relationship in primitive society. Comparatively, the two references are much more unlikely to suffer from structural collapse than Dong and Miao settlements. Besides, the relatively small and clustered dimensions of the latter might have something to do with the differentiation and hierarchization of close relationships, which is induced by the complicate factors affecting the spatial structure of the settlements. These two changes are the signs of social progress.

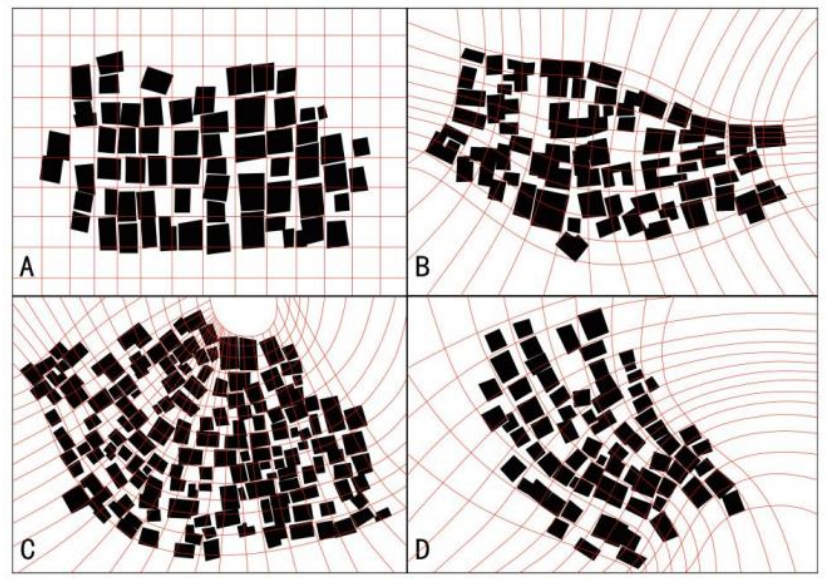

Figure 11. Various matrix topologies of the spatial structure for Dong Settlements
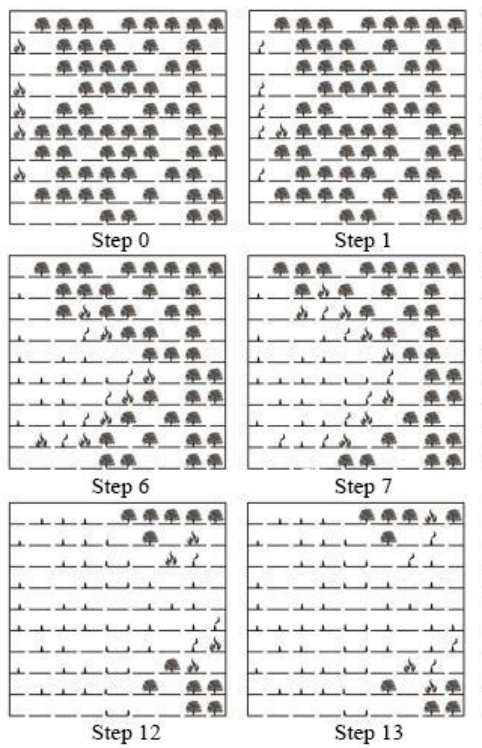

Trees
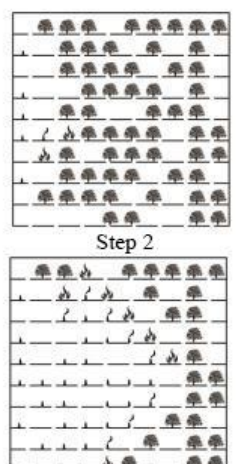

Step 8

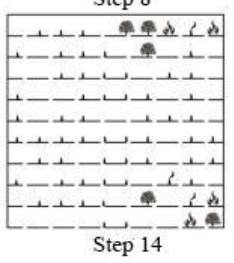

d) Burning trees
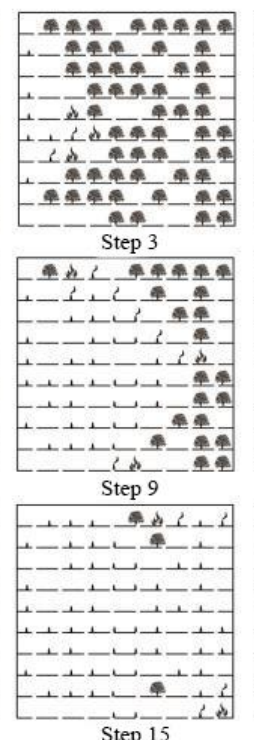

$\{$ Burned trees
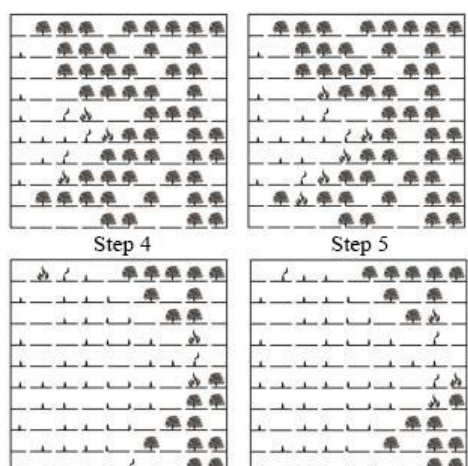

Step 10

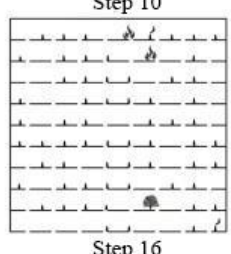

$\perp$ Stumps

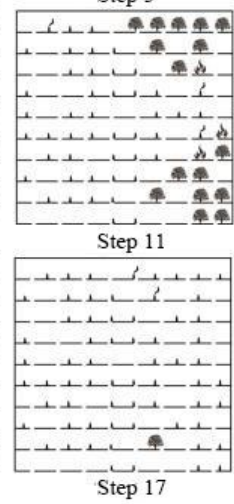

Figure 12. Simulation of a forest fire in the critical state of seepage flow

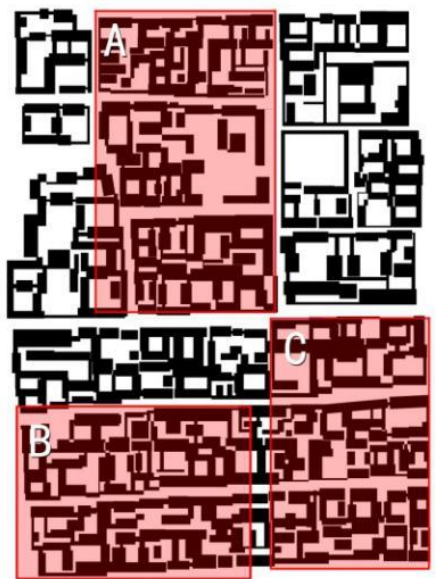

Figure 13. Courtyard settlement in Fuxingmennei region, Beijing

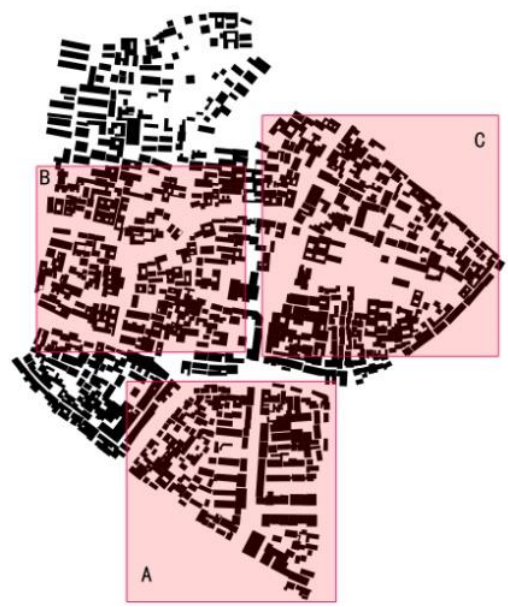

Figure 14. Tongli Town settelement, Jiangsu 


\subsection{Fire prevention strategies}

For traditional settlements, fire seepage involves macroscale structural seepage and microscale issues like fire separation distance, mode of construction, and material flammability. In fact, the fire can be prevented effectively by microscale measures, such as spacing control, mode alteration, and increase of fire resistance rating. But these measures will also reshape the spatial structure, and damage the traditional features.

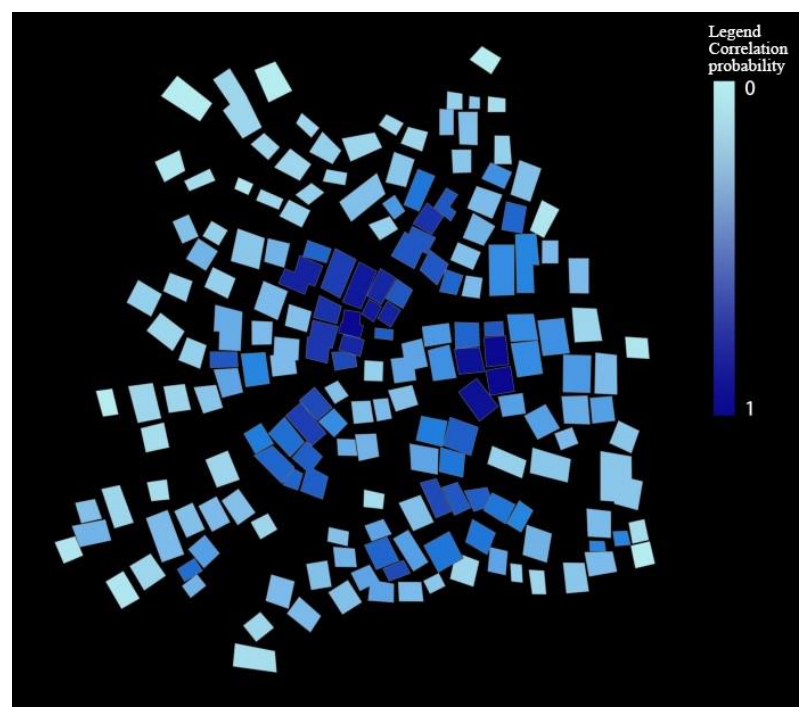

Figure 15. Distribution of relative correlation probabilities of fire

Based on seepage theory, fire seepage is essentially a systematic problem caused by the distribution of the combustion probabilities of elements in the settlement. Taking the spacing (d) and inflammability ( $\mathrm{t}$ ) of buildings in Gunda Village as parameters, the distribution of relative correlation probabilities for the fire seepage under the combined effect of the two parameters was simulated on MATLAB. From the structural level, the simulation results (Figure 15) accurately depict the probability distribution and association paths of the fire seepage for the settlement system, providing a clear guide for fire prevention from the root and risk prediction with a high precision. On this basis, several preliminary measures were presented for fire prevention:

On the macro-level, referring to the risk map, the combustible elements, and the overall spatial structure, the settlement should classify, merge, and partition its main fire seepage clusters, and take targeted measures to cut off the weak links between large seepage clusters, thereby preventing the spread of structural fire.

On the micro-level, facing the complexity of fire prevention, the traditional settlement should rather than sticking to only one fire prevention measure, but work to reduce the overall probability of fire, in the light of the risk map and the combustible elements. Under the premise of preserving the regional features, the traditional settlement should test the effect of the combination between multiple factors, such as spatial structure, material position, fireproof construction, and building spacing, and choose the combination with the minimum impact on traditional feature, and the minimum overall probability of fire seepage. This combination of multiple factors would effectively reduce seepage correlation and seepage rate, lower fire intensity and spread rate, curb the systematic accumulation of fire factors, and eliminate structural fires.

In addition, it is necessary to strictly control the initial fire point. Putting out the fire in the initial phase is the most effective and least costly strategy of settlement fire protection. The initial phase of fire has a high probability of seepage flow. To prevent structural fire, it is of paramount importance to strictly monitor and control this phase.

\section{CONCLUSIONS}

The spatial structure of traditional Dong and Miao settlements is a quasi-seepage critical topology matrix. Under this spatial structure, a fire could accumulate systematically in the settlement, causing the settlement structure to collapse quickly. From the angle of fractal and seepage theory, this paper takes the typical Dong and Miao settlements in traditional Chinese villages as the object, investigates the influencing factors and mechanism for the fire propagation across the timber buildings in traditional settlements, discusses the genetic mechanism of the fire from the structural angle, and then proposes targeted fire prevention measures based on the probability map. The experimental results confirm that both the random combustible elements and the settlements have clear fractal structures, reveal the influence of fire source location over the fire propagation across the timber buildings in traditional settlements, and disclose the law of fire spread among these buildings.

\section{ACKNOWLEDGMENT}

This work is supported by The Natural Science Foundation of Hebei Province of China (Grant No.: E2019201230), The National Natural Science Foundation of China (Grant No.: 51708378), The Natural Science Foundation of Jiangsu Province of China (Grant No.: BK20170381).

\section{REFERENCES}

[1] Cao, F., Meng, M., Shan, B., Sun, R. (2021). Source apportionment of mercury in surface soils near the Wuda coal fire area in Inner Mongolia, China. Chemosphere, 263:

128348 . https://doi.org/10.1016/j.chemosphere.2020.128348

[2] Su, Z., Hu, H., Wang, G., Ma, Y., Yang, X., Guo, F. (2018). Using GIS and random forests to identify fire drivers in a forest city, Yichun, China. Geomatics, Natural Hazards and Risk, 9(1): 1207-1229. https://doi.org/10.1080/19475705.2018.1505667

[3] Chen, M., Wang, K., Dong, X., Li, H. (2020). Emergency rescue capability evaluation on urban fire stations in China. Process Safety and Environmental Protection, 135: 59-69. https://doi.org/10.1016/j.psep.2019.12.028

[4] Hu, M., Liu, Y., Wang, T., Hao, Y., Li, Z., Wan, S. (2020). Fire alters soil properties and vegetation in a coniferous-broadleaf mixed forest in central China. Forests, 11(2): 164. https://doi.org/10.3390/f11020164

[5] Li, J., Bo, Y., Xie, S. (2016). Estimating emissions from crop residue open burning in China based on statistics and MODIS fire products. Journal of Environmental Sciences,

44:

$158-170$ 
https://doi.org/10.1016/j.jes.2015.08.024

[6] Han, J., Shen, Z., Ying, L., Li, G., Chen, A. (2015). Early post-fire regeneration of a fire-prone subtropical mixed Yunnan pine forest in Southwest China: Effects of prefire vegetation, fire severity and topographic factors. Forest Ecology and Management, 356: 31-40. https://doi.org/10.1016/j.foreco.2015.06.016

[7] Zhao, H., Li, X., Hall, V.A. (2015). Holocene vegetation change in relation to fire and volcanic events in Jilin, Northeastern China. Science China Earth Sciences, 58(8): 1404-1419. https://doi.org/10.1007/s1 1430-015-5068-8

[8] Liu, M., Song, Y., Yao, H., Kang, Y., Li, M., Huang, X., $\mathrm{Hu}, \mathrm{M}$. (2015). Estimating emissions from agricultural fires in the North China Plain based on MODIS fire radiative power. Atmospheric Environment, 112: 326334. https://doi.org/10.1016/j.atmosenv.2015.04.058

[9] Wu, Z., He, H.S., Yang, J., Liang, Y. (2015). Defining fire environment zones in the boreal forests of northeastern China. Science of the total environment, 518: $106-116$ https://doi.org/10.1016/j.scitotenv.2015.02.063

[10] Su, W.H., Shi, Z., Zhou, R., Zhao, Y.J., Zhang, G.F. (2015). The role of fire in the Central Yunnan Plateau ecosystem, southwestern China. Forest Ecology and Management, 356: 22-30. https://doi.org/10.1016/j.foreco.2015.05.015

[11] Cui, S., Song, Z., Zhang, L., Shen, Z., Hough, R., Zhang, Z., An, L., Fu, Q., Zhao, Y., Jia, Z. (2021). Spatial and temporal variations of open straw burning based on fire spots in northeast China from 2013 to 2017 . Atmospheric Environment, 244: 117962. https://doi.org/10.1016/j.atmosenv.2020.117962

[12] Xu, X., Li, F., Lin, Z., Song, X. (2021). Holocene fire history in China: Responses to climate change and human activities. Science of The Total Environment, 753: 142019. https://doi.org/10.1016/j.scitotenv.2020.142019

[13] Liang, M., Liang, Y., Liang, H., Rao, Z., Cheng, H.
(2018). Polycyclic aromatic hydrocarbons in soil of the backfilled region in the Wuda coal fire area, Inner Mongolia, China. Ecotoxicology and Environmental Safety, 165: 434-439. https://doi.org/10.1016/j.ecoenv.2018.08.065

[14] Ying, L., Han, J., Du, Y., Shen, Z. (2018). Forest fire characteristics in China: Spatial patterns and determinants with thresholds. Forest Ecology and Management, 424: 345-354. https://doi.org/10.1016/j.foreco.2018.05.020

[15] Huang, W., Hu, Y., Chang, Y., Liu, M., Li, Y., Ren, B., Shi, S. (2018). Effects of fire severity and topography on soil black carbon accumulation in boreal forest of Northeast China. Forests, 9(7): 408. https://doi.org/10.3390/f9070408

[16] Hong, H., Tsangaratos, P., Ilia, I., Liu, J., Zhu, A. X., Xu, C. (2018). Applying genetic algorithms to set the optimal combination of forest fire related variables and model forest fire susceptibility based on data mining models. The case of Dayu County, China. Science of the Total Environment, 630: 1044-1056. https://doi.org/10.1016/j.scitotenv.2018.02.278

[17] Qin, X.L., Li, X.T., Liu, S.C., Liu, Q., Li, Z.Y. (2020). Forest fire early warning and monitoring techniques using satellite remote sensing in China. Journal of Remote Sensing, 24(5): 511-520. https://doi.org/10.11834/jrs.20209135

[18] Tian, X., Cui, W., Shu, L. (2020). Evaluating fire management effectiveness with a burn probability model in Daxing'anling, China. Canadian Journal of Forest Research, 50(7): 670-679. https://doi.org/10.1139/cjfr2019-0413

[19] Guo, L., Ma, Y., Tigabu, M., Guo, X., Zheng, W., Guo, F. (2020). Emission of atmospheric pollutants during forest fire in boreal region of China. Environmental Pollution, 264: 114709 . 